\title{
Effect of Combined Dietary Supplementation of Telfairia Occidentalis Leaves and Citrulus Colocynthis Seeds on Fasting Glycemia, Glucose Tolerance and Body Weight in Wistar Rats
}

\author{
Etoundi Omgba BC*, Palla Nyamena CL, Manz Koulea CJ and Gouadoa I \\ Department of Biochemistry, University of Douala, Douala, Cameroon \\ *Corresponding author: Etoundi Omgba BC, Department of Biochemistry, Faculty of Science, University of Douala, Douala, Cameroon, Tel: (+237) 695 41 89 79; E- \\ mail: blancheetoundi@hotmail.fr
}

Received date: January 28, 2017; Accepted date: March 21, 2017; Published date: March 28, 2017

Copyright: ( $) 2017$ Omgba EBC, et al. This is an open-access article distributed under the terms of the Creative Commons Attribution License, which permits unrestricted use, distribution, and reproduction in any medium, provided the original author and source are credited.

\begin{abstract}
Though medical assistance can be given to diabetic patients, dietary care is highly explored. This work aimed at studying the effects of dietary supplementation of uncooked Telfairia occidentalis leaves combined with Citrulus colocynthis seeds on blood glucose level in Wistar rats. A phytochemical screening was realized on T.occidentalis ethanolic and hydroethanolic leaves extracts, and their acute toxicity was studied in rats. The effect of their combined dietary supplementation on glycemia and body weight was studied in rats receiving carbohydrate enriched diet during 28 days. Three test groups received 10\% Telfairia occidentalis leaves, $10 \%$ C.colocynthis and a mixture of $5 \%$ T.occidentalis leaves and $5 \%$ C. colocynthis respectively. Glibenclamide $(0.03 \mathrm{mg} / \mathrm{kg}$ b.w) was used as reference drug.

Glucose tolerance was tested at the end of supplementation period. The presence of tannins, saponins, anthocyanines and flavonoids was revealed in T. occidentalis extracts and no sign of toxicity was identified in rats. Fasting glycemia decreased significantly in rats supplemented with $T$. occidentalis as compared to positive control and there was no significant increase in glycemia for rats supplemented with $C$. colocynthis and with both plants. All animals except the positive control showed a good glucose tolerance at the end of supplementation. T. occidentalis showed hypoglycemic properties and its association with $C$. colocynthis inhibited hyperglycemia and maintained good glucose tolerance. Hence, combined consumption of T. occidentalis leaves with C. colocynthis seeds might be advised in diabetes management.
\end{abstract}

Keywords: Telfairia occidentalis; Citrulus colocynthis; Dietary supplementation; Antihyperglycemic activity; Diabetes management

\section{Introduction}

Diabetes mellitus is a multifactorial disease which arises when there is a disorder in insulin secretion and/or action. It is highly related to diet, genetics and lifestyle. Its main symptom and consequence is a chronic hyperglycemia [1] which is harmful in various ways to human health. Nowadays, it is very prevalent and about $80 \%$ of people suffering from diabetes are found in less developed countries [2]. Poor management of diabetes may lead to serious complications and dysfunctionning of other vital organs in the body [3].

Medical care and dietary care are some examples of diabetes management nowadays. However medical care might not be quite affordable to all social class and it may lead to side effects. Many researches had been carried out to study the potential of certain plant in diabetes management [4].

Telfairia occidentalis (To) is a Curcubitacea which is cultivated for its edible leaves and grains. It has been shown to have antihyperglyceamic and hypoglycemic activities by previous studies [5]. In Cameroon, it is often consumed in Anglophone regions with Citrulus colocynthis $(\mathrm{Cc})$ seeds commonly called "egusi".

The latter has also been reported to possess antidiabetic activities through the insulin mimetic properties of some of its phytoconstituents [6,7]. This study aims at evaluating the effect of the combined dietary supplementation of Telfairia occidentalis leaves with Citrullus colocynthis seeds on blood glucose and body weight in wistar rats.

\section{Methodology}

\section{Plant material}

Telfairia occidentalis leaves and Citrulus colocynthis seeds were collected from local markets in Douala and Mbanga towns respectively, in the Littoral region in Cameroon. The leaves were shed dried and the seeds were sundried. Both were ground separately and stored at room temperature.

\section{Preparation of T. occidentalis leaves $C$. colocynthis seed extracts}

Ethanolic and hydro ethanolic extracts were prepared by soaking $250 \mathrm{mg}$ of T. occidentalis leaves in $1500 \mathrm{ml}$ of solvent (ethanol and a mixture of water/ethanol in the ration 1:1) for maceration in the dark, at room temperature during 48 hours. The mixture was then filtered and the filtrates were concentrated by drying in an owen at $45^{\circ} \mathrm{C}$ during 4 days. 
Citation: Etoundi Omgba BC, Palla Nyamena CL, Manz Koulea CJ, Gouadoa I (2017) Effect of Combined Dietary Supplementation of Telfairia Occidentalis Leaves and Citrulus Colocynthis Seeds on Fasting Glycemia, Glucose Tolerance and Body Weight in Wistar Rats. J Nutr Disorders Ther 7: 209. doi:10.4172/2161-0509.1000209

Page 2 of 4

\section{Phytochemical screening}

A phytochemical screening was realized on T. occidentalis ethanolic and hydro ethanolic leaves extract to determine the presence of tannins [8], flavonoids [9] and anthocyanines [10].

\section{Experimental animals}

Wistar rats aged of 3 months were bought from the Laboratory of Animal Biology in the University of Douala. They were kept in metabolic cages under a 12 hours dark/light cycle at room temperature for 2 weeks before any experimentation. They received standard laboratory chow and water ad libitum.

\section{Acute toxicity assay}

The acute toxicity of ethanolic and hydroethanolic extract of $T$. occidentalis leaves and $C$. colocynthis seeds was evaluated with the limit test dose at $2000 \mathrm{mg} / \mathrm{kg}$ body weight according to guideline 425 of Organization for Economic Cooperation and Development [11]. Female rats were used as they are reported to be more sensitive during toxicity assay [12].

Five groups of 5 rats each were used, of which the control received distilled water and the test groups received a single oral administration of various extracts at $2000 \mathrm{mg} / \mathrm{kg}$ body weight. Signs of toxicity were monitored during 14 days after which animals were humanely sacrificed and their blood collected. The commercial kit IMNESCO was used for determination of ASAT (Aspartate transaminase), ALAT (Alanine transaminase).

\section{Effect of dietary supplementation of T. occidentalis leaves and $C$. colocynthis seeds on glycemia and body weight in Wistar rats}

Six groups of 4 male rats each (positive control, 3 test groups, reference group and negative control) were used.

Male were used for this test as they do not have rich hormonal cycle. After 12 hours of overnight fasting, their glycemia was measured. During 28 days, all groups except the negative control, received $65 \%$ sucrose enriched food, $10 \%$ glucose in drinking water and oral administration of fructose $(1 \mathrm{~g} / \mathrm{kg})$. The standard laboratory chow was supplemented with $10 \%$ of $T$. occidentalis powdered leaves, $10 \% \mathrm{C}$. colocynthis seeds and a mixture of 5\% T. occidentalis and 5\% C. colocynthis for the three test groups respectively.

Glibenclamide $(0.3 \mathrm{mg} / \mathrm{kg})$ was administered orally to the reference group and fasting glycemia was measured on days 1, 9, 18 and 28 for all animals.

\section{Oral glucose tolerance test at the end of supplementation period}

At the end of experimental period, all animal were fasted overnight and oral glucose tolerance test was carried out. Their fasting glycemia was measured after what they received a glucose solution at $2 \mathrm{~g} / \mathrm{Kg}$ b.w. Their blood glucose was then measured at 30 minutes interval during two hours.

\section{Statistical analysis}

STATGRAPHICS CENTURION XV.II and SPSS 17 were used for statistical analyses. Variables are presented as mean \pm standard deviation. Data were analyzed by the one way analyses of variance test (ANOVA) followed by the least significant difference (LSD) post Hoc test. Values of $\mathrm{p}<0.05$ were considered significant.

\section{Results}

\section{Phytochemical screening}

\begin{tabular}{|l|l|l|l|}
\hline & Anthocyanin & Flavonoids & Saponins \\
\hline Ethanolic extract & - & + & + \\
\hline Hydroethanolic extract & + & + & + \\
\hline
\end{tabular}

Table 1: phytochemical screening of T. occidentalis leaves extracts.

The Table 1 shows the results of the phytochemical screening.

\section{Acute toxicity assay}

After two weeks observation, no sign of toxicity was observed in rats. Furthermore, the evaluation of plasmatic transaminases showed no significant difference in test groups as compared to control for AST, but instead lead to significant decrease for ALT in test groups (Figure $1)$.

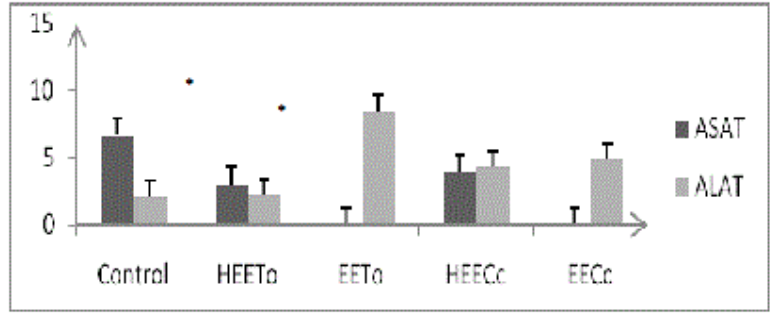

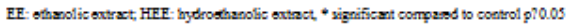

Figure 1: Biological toxicity parameters.

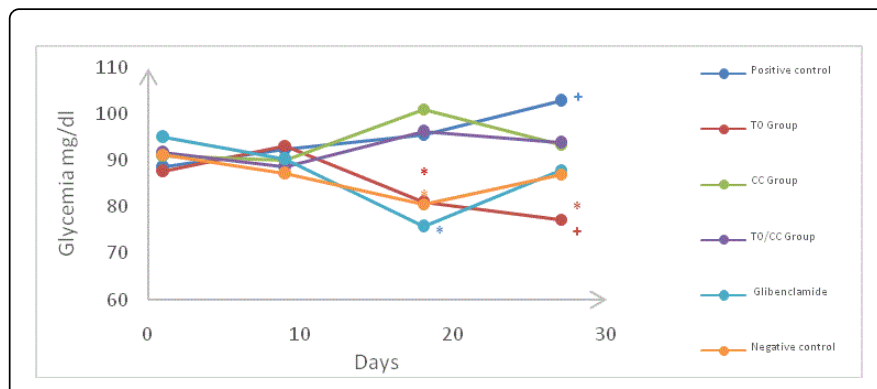

Figure 2: Glycemia evolution in rats during supplementations. +significant compared to 1st day; + significant compared to 9th day; ${ }^{*}$ significant compared to positive control.

\section{Effects of dietary supplementation of T. occidentalis and $C$. colocynthis on blood glucose and body weight}

Figure 2 shows the evolution of glycemia in various groups at 9 days intervals. Rats receiving only carbohydrate enriched diet (sucrose, 
Citation: Etoundi Omgba BC, Palla Nyamena CL, Manz Koulea CJ, Gouadoa I (2017) Effect of Combined Dietary Supplementation of Telfairia Occidentalis Leaves and Citrulus Colocynthis Seeds on Fasting Glycemia, Glucose Tolerance and Body Weight in Wistar Rats. J Nutr Disorders Ther 7: 209. doi:10.4172/2161-0509.1000209

Page 3 of 4

glucose and fructose) showed a significant increase in fasting glycemia from the 1 st to the last day with mean glycemia of $102.83 \pm 12.4 \mathrm{mg} / \mathrm{dl}$, thus corresponding to an impaired fasting blood glucose.

Rats receiving only To showed significant decrease in glycemia compared to positive control on the 9th day. Those receiving both plants have a non-significant change in glycemia compared to first day.

On the other hand the glycemia of the positive control was in continual increase throughout the study period.

Throughout the experimental period, there was no significant difference in body weight for all groups of animals. The values are reported in Table 2 .

\section{Oral glucose tolerance test (OGTT) at the end of supplementation period}

Two hours after receiving a glucose solution at a dose of $2 \mathrm{~g} / \mathrm{kg}$ body weight, all groups of rats returned to normal glycemic values as reported in Table 3.
This implies that they all had a normal glucose tolerance.

\begin{tabular}{|l|l|l|l|l|l|}
\hline & Day 1 & Day 7 & Day 14 & Day 21 & Day 28 \\
\hline Animal groups & \multicolumn{3}{|l|}{ Body weight (g) } \\
\hline Pc & $246 \pm 31$ & $235 \pm 29$ & $233 \pm 12$ & $238 \pm 28$ & $228 \pm 28$ \\
\hline To(10\%) & $246 \pm 33$ & $228 \pm 17$ & $230 \pm 24$ & $224 \pm 29$ & $216 \pm 31$ \\
\hline Cc(10\%) & $246 \pm 35$ & $230 \pm 30$ & $226 \pm 21$ & $239 \pm 25$ & $232 \pm 25$ \\
\hline To(5\%)/Cc(5\%) & $247 \pm 35$ & $223 \pm 33$ & $223 \pm 33$ & $234 \pm 39$ & $227 \pm 35$ \\
\hline Gli & $246 \pm 47$ & $230 \pm 44$ & $224 \pm 42$ & $234 \pm 39$ & $236 \pm 37$ \\
\hline Nc & $246 \pm 39$ & $238 \pm 36$ & $225 \pm 39$ & $240 \pm 28$ & $232 \pm 27$ \\
\hline $\begin{array}{l}\text { Values are expressed as mean } \pm \text { SD, n=4. They were analysed using ANOVA } \\
\text { (test p<0.05). Pc: positive control; To: Telfairia occidentalis; Cc: Citrulus } \\
\text { colocynthis; gli: glibenclamide; Nc: negative control. }\end{array}$ \\
\hline
\end{tabular}

Table 2: Animals' body weight evolution during supplementation.

\begin{tabular}{|c|c|c|c|c|c|}
\hline \multirow[t]{2}{*}{ Animal groups } & TO & $\mathrm{T} 30 \mathrm{~min}$ & T60min & T90min & T120min \\
\hline & \multicolumn{5}{|c|}{ Glycemia(mg/dl) } \\
\hline $\mathrm{Pc}$ & $98.6 \pm 7.9$ & $109.2 \pm 5.2$ & $114.7 \pm 8.2^{*}$ & $99.6 \pm 5.3 x$ & $93.3 \pm 14.5+x$ \\
\hline TestTo & $77.7 \pm 5.7$ & $126.2 \pm 31.5^{\star}$ & $98.8 \pm 22.6$ & $102.3 \pm 15.9$ & $94.7 \pm 18.1+$ \\
\hline TestCc & $93.5 \pm 16.2$ & $119.2 \pm 12.5^{\star}$ & $114.0 \pm 8.2^{*}$ & $99.3 \pm 5.2 x$ & $88.4 \pm 9.9+x$ \\
\hline TestTo/Cc & $93.8 \pm 11.1$ & $110.8 \pm 29.6$ & $118.0 \pm 10.8^{*}$ & $106.3 \pm 23.2$ & $84.4 \pm 11.3+$ \\
\hline TestGli & $93.2 \pm 18.5$ & $115.3 \pm 12.6^{*}$ & $104.8 \pm 8.7$ & $81 \pm 11.9+x$ & $79.1 \pm 8.2+x$ \\
\hline Nc & $93.8 \pm 4.6$ & $83.3 \pm 6.9$ & $72.92 \pm 1.9^{*}$ & $72.9 \pm 1.3^{*}$ & $63.8 \pm 14.1^{*}+x$ \\
\hline
\end{tabular}

Values are expressed as mean $\pm S D, n=4$. They were analysed using ANOVA (test $p<0.05)$. *significant compared to T0; $x$ Significant compared to T30 min; + significant compared to T60 min.Pc: positive control; To: Telfairia occidentalis; Cc: Citrulus colocynthis; Gli: Glibenclamide; Nc: negative control.

Table 3: Evolution of blood glucose during oral glucose tolerance test at the end of supplementation.

\section{Discussion}

The phytochemical screening revealed the presence of flavonoids, tannins, saponin in both extracts but anthocyanins were revealed only in the hydro ethanolic extract. This might be due to compound's affinity with the solvent used. However, all these compounds are reported to possess hypoglyceamic effects [13]. No sign of toxicity was observed on experimental rats after receiving various extracts at a single dose of $2000 \mathrm{mg} / \mathrm{kg}$ b.w., thereby showing that our plants were nontoxic. This result is in accordance with previous studies [14,15]. Moreover, the ethanolic extracts for both plants caused a significant difference in ALAT suggesting hepato protective properties.

During the experimental period, rats receiving carbohydrate enriched diet showed a significant increase in fasting blood glucose. This result could be explained by the fact that the carbohydrate (glucose, sucrose, fructose) rich diet contributes in increasing blood glucose hence causing hyperglycemia $[16,17,18]$. Blood glucose was reduced significantly in rats supplemented with To and it was maintained within normal values in those supplemented with both plants. This result suggests the Inhibitory effect of the combined supplementation on increasing fasting blood glucose led by the carbohydrate enriched diet. These results might be due to the presence of anti-glycemic compounds in both plants [6,7,13]. Moreover, Cc seeds regulate the activity of several enzymes involved in glycolysis as reported by Jeyanthi and Christy, thereby accounting for their antihyperglycemic effect [19].

The Oral Glucose Tolerance Test (OGTT) measures the body's ability to use up glucose. Apart from using fasting blood glucose alone, OGTT was seen as a practical attempt to simplify and facilitate the diagnosis of diabetes [20]. An oral glucose tolerance test helps in checking on the ability of an organism to regulate blood glucose $2 \mathrm{hrs}$ after receiving $2 \mathrm{~g} / \mathrm{Kg}$ b.w. At the end of experimental period, all animals returned to a normal glycemia during an oral glucose tolerance test. This suggests that the combined supplementation of both plants helped to maintain the glucose regulatory capacity or glucose tolerance to normal.

\section{Conclusion}

Results from this work showed that Telfairia occidentalis leaves possess phytochemicals which are reported to have anti diabetic properties. Extracts of both plants (To and $\mathrm{Cc}$ ) were revealed to be non-toxic. Therefore, referring to the facts that, during the supplementation assay and the oral glucose tolerance test, the glycemia 
Citation: Etoundi Omgba BC, Palla Nyamena CL, Manz Koulea CJ, Gouadoa I (2017) Effect of Combined Dietary Supplementation of Telfairia Occidentalis Leaves and Citrulus Colocynthis Seeds on Fasting Glycemia, Glucose Tolerance and Body Weight in Wistar Rats. J Nutr Disorders Ther 7: 209. doi:10.4172/2161-0509.1000209

Page 4 of 4

of the tests groups consuming the combination of $T$. occidentalis leaves and $C$. Colocynthis seeds remain normal despite the higher charge of carbohydrates, we could recommend it for the prevention and management of hyperglycemia and diabetes.

\section{References}

1. Chukwunonso ECCE, Nnamdi KU, Stella ON (2015) Diabetes and pre diabetes in adult Nigerians: prevalence and correlation of blood glucose concentration. Afri J Biochem Res 9: 55-60.

2. Fédération Internationale du Diabète (2013) Atlas du diabète de la FID. 6e ed.

3. Sapna S, Tamilarasi A, Pravin K (2012) Implementation of genetic algorithm in predicting diabetes. Int J Comput Sci 9: 234-240.

4. Ahmad G (2013) Best herbs for managing diabetes: a review of clinical studies. Braz J Pharm Sci 49: 413-422.

5. Eseyin OA, Munavvar AS, Hassaan AR (2014) A Review of the pharmacological and biological activities of the aerial parts of Telfairia occidentalis Hook.f. (Cucurbitaceae). Trop J Pharm Res 13: 1761-1769.

6. Patel DK, Prasad SK, Kumar R, Hemalatha S (2012) An overview on antidiabetic medicinal plants having insulin mimetic property. Asian Pac J Trop Biomed 2: 320-330.

7. Borhade P, Deshmukh T, Patil V, Khandelwal K (2013) Review on Citrullus colocynthis. Int J Res Pharm Chem 3: 46-53.

8. Trease GE, Evan WE (1989) Trease and Evans Pharmacognosy. A Physician guide to herbal medicine (15th ed) London: Baillere Tindall Ltd

9. Trease, GE, Evan WE (1989) A text book of pharmacognosy (13th ed) London.

10. Harbone JB (1967) Comparative biochemistry of the flavonoids. LondonNew York: Academic Press.
11. Organization for Economic Cooperation and Development (2008) Test No. 425: Acute Oral Toxicity: Up-and-Down Procedure. OECD Guidelines for the Testing of Chemicals, Section 4. OECD Publishing. Paris.

12. Organization for Economic Cooperation and Development (2001) No. 423: Acute Oral Toxicity-Acute Toxic Class Method. OECD Guidelines for the Testing of Chemicals.

13. Cristina C, Olivia DR, Carmen S (2012) Plants and natural compounds with antidiabetic action. Not Bot Horti Agrobot 40: 314-325.

14. Ojo NA, Adawaren EO, Tijjani MB, Chiroma M, Simon J, et al. (2012) Acute toxicity and effect of ethanolic extract of Tefairia occidentalis leaves on blood glucose level in normal rats. Vom J Vet Sci 9: 25-31.

15. Ekpenyong CE, Akpan EE, Udoh NS (2012) Phytochemistry and toxicity studies of Telfairia occidentalis aqueous leaves extract on liver biochemical indices in wistar rats. Am J Med Med Sci 2: 103-110.

16. Tappy L (2012) Q\&A 'Toxic' effects of sugar: should we be afraid of fructose. BMC Bio10: 42.

17. Raquel SC, Ana BTA-W, Fernando A, Rosana CTM, Ubiratan FM (2012) Carbohydrate- and lipid-enriched meals acutely disrupt glycemic homeostasis by inducing transient insulin resistance in rats. Can J Physiol Pharmacol 90: 537-545.

18. Lecoultre V, Egli L, Carrel G, Theytaz F, Kreis R, et al. (2013) Effects of fructose and glucose overfeeding on hepatic insulin sensitivity and intra hepatic lipids in healthy humans. Obesity 21: 782-785.

19. Jeyanthi KA, Christy A Mary Violet (2009) Antihyperglycemic Effect of Citrullus colocynthis Seed Powder in Alloxan-Induced Diabetic Rats. IUP J Biotech 3: 30.

20. Anitha M, Sakthidevi G, Muthukumarasamy S, Mohan VR (2012) Effect of Cynoglossum zeylanicum (Vehl ex Hornem) Thunb. Ex Lehm on Oral Glucose Tolerance in rats. J Appl Pharm Sci 2: 075-078. 